\title{
The modified early age strains development model for the case of two-way restraint conditions
}

\author{
Volha Sannikava ${ }^{1 *}$, Viktar Tur ${ }^{1}$ \\ ${ }^{1}$ Brest State Technical University, Moskovskaya 267, Brest 224017, Belarus
}

\begin{abstract}
This paper proposes a design model (2D MSDM) for assessment the early-age stress-strain parameters of two-axially restrained expansive concrete elements. The analytical model allows defining the restrained expansion strains and corresponding self-stresses in case of arbitrary restraint conditions in orthogonal directions by taking into consideration the elastic-plastic behavior of concrete during the expansion period. The results of solution according to the proposed model were compared with the experimental results of expansive concrete elements with orthogonal confinement carried out by authors and other researchers.
\end{abstract}

\section{Introduction}

Although Ordinary Portland Cement concrete is one of the most universal and most widely used construction materials, it is not without disadvantages. Shrinkage is an inherent characteristic and while we try to eliminate or at least minimize this shortcoming, it is still present. Along with the low tensile strength of the material, shrinkage induces cracks of varying sizes in almost every reinforced concrete structure. Expansive concrete was developed as a suitable material not only for compensating the inevitable shrinkage strains in concrete but also for inducing its own restrained strains and the pre-stresses (selfstresses) in reinforced concrete structures. The increase of expansive concrete in volume under restraint conditions during the hardening period produces the initial elastic compressive strains in concrete and tensile strains in confinement so leading to the socalled physico-chemical prestress of structure. This phenomenon makes the expansive concrete very useful for reinforced concrete structures produced in building site conditions.

It should be noted that in many cases of practical application of expansive concrete in structural elements (for example, floor slabs in warehouses, pavements, concrete pipes, reservoirs, etc.) the free expansion deformations of material are restrained by two-way and three-way oriented reinforcement. Comprehensive analysis of well-known design models for calculation the early-age stress-strain parameters of two-axially restrained expansive concrete elements has revealed a number of disadvantages [1, 2]. For example, models based on the chemical energy conservation law [3-5] accept the design self-stress of

* Corresponding author: volhasann@gmail.com 
expansive concrete as a basic parameter although a different correlation between the values of free expansion strains and self-stressing grade arises. Formulas proposed in empirical exponential function models [6] and semi-empirical models [7] are based on the experimental results carried out using the prismatic or cubic samples but don't consider the scale factor. All design formulas in models [3-7] contain the empirical coefficients that are based on the limited experimental data that can lead to incorrect results with respect to the wide range of expansive concrete elements under two-way restraint conditions. Additionally, most of models [3-6] allows determining the restrained expansion strains only by the end of the expansive concrete stabilization and doesn't consider the elastic-plastic behavior of material at early-ages.

In that way, the assessment of restrained strains and self-stresses is still a matter of concern for expansive concrete elements with reinforcement oriented in orthogonal directions.

\section{Basic provisions of the design model 2D MSDM}

An alternative concept was developed in researches [8] and was completed for the case of uniaxial restraint conditions in the model MSDM [9]. The distinguishing feature of the MSDM consists in taking into account the elastic cumulative force induced by the restraint at the end of preceding time interval.

According to the MSDM for expansive concrete elements under uniaxial restraint conditions [9], the restrained expansion strain at any $i$-th time interval $\varepsilon_{s}\left(t_{i+1 / 2}\right)$ can be performed as an algebraic sum in the next view:

$$
\varepsilon_{s}\left(t_{i+1 / 2}\right)=\varepsilon_{c f}\left(t_{i+1 / 2}\right)+\varepsilon_{e l}\left(t_{i+1 / 2}\right)+\varepsilon_{p l}\left(t_{i+1 / 2}, t_{0}\right)+\varepsilon_{c u m}\left(t_{(i-1)+1 / 2}\right)
$$

where $\varepsilon_{c f}\left(t_{i+1 / 2}\right)$ - the free expansion strain;

$\varepsilon_{e l}\left(t_{i+1 / 2}\right)$ - elastic strain at $i$-th time interval;

$\varepsilon_{p l}\left(t_{i+1 / 2}, t_{0}\right)$ - creep strain at $i$-th time interval under constant self-stress applied at $t_{0}$ days;

$\varepsilon_{\text {cum }}\left(t_{(i-1)+1 / 2}\right)$ - additional strain caused by the restrictive force induced by the restraint at $(i-1)$-th time interval.

When performing the expansive concrete elements under two-way restraint conditions the interference between longitudinal and transverse strains should be taken into consideration. It's a well-known fact from the theory of elasticity that in plain elastic elements the Poisson's ratio is applied to calculate the strains in one orthogonal direction in the presence of the strain in another direction. Since expansive concrete is elastic-plastic material and, as could be seen from the formula (1), only part of general strain has the elastic origin, so the Poisson's ratio should be applied concerning the elastic strain at $i$-th time interval $\varepsilon_{e l}\left(t_{i+1 / 2}\right)$. Based on the results of investigations presented in papers [10-13], in proposed design model (2D MSDM) the value of the Poisson's ratio equals $v=0.2$.

There are three main assumptions with regard to the design model 2D MSDM for assessment the restrained strains and self-stresses in expansive concrete elements under two-way restraint conditions:

1) confinement in orthogonal directions is considered applying the Poisson's ratio of early age expansive concrete $v=0.2$ with respect to the elastic strain at $i$-th time interval $\left(\varepsilon_{\text {el. }}\left(t_{i+1 / 2}\right)\right.$ in direction $X, \varepsilon_{\text {el. } y}\left(t_{i+1 / 2}\right)$ in direction $Y$ );

2) restrained expansion strain at any $i$-th time interval in any orthogonal direction is presented as an algebraic sum of free expansion strain $\left(\varepsilon_{c f}\left(t_{i+1 / 2}\right)\right)$, elastic strain $\left(\varepsilon_{e l . x}\left(t_{i+1 / 2}\right)\right.$ 
in direction $X, \varepsilon_{\text {el. } y}\left(t_{i+1 / 2}\right)$ in direction $\left.Y\right)$, creep strain $\left(\varepsilon_{p l . x}\left(t_{i+1 / 2}, t_{0}\right)\right.$ in direction $X$, $\varepsilon_{p l . y}\left(t_{i+1 / 2}, t_{0}\right)$ in direction $\left.Y\right)$ at $i$-th time interval and additional strain caused by the restrictive force induced by the restraint $\left(\varepsilon_{\text {cum.x } x}\left(t_{(i-1)+1 / 2}\right)\right.$ in direction $X, \varepsilon_{\text {cum.y }}\left(t_{(i-1)+1 / 2}\right)$ in direction $Y$ ) at (i-1)-th time interval (figure 1):

$$
\left\{\begin{array}{l}
\varepsilon_{s . x}\left(t_{i+1 / 2}\right)=\varepsilon_{c f}\left(t_{i+1 / 2}\right)+\left[\varepsilon_{\text {el. }}\left(t_{i+1 / 2}\right)-v \cdot \varepsilon_{e l . y}\left(t_{i+1 / 2}\right)\right]+\varepsilon_{p l . x}\left(t_{i+1 / 2}, t_{0}\right)+\varepsilon_{c u m . x}\left(t_{(i-1)+1 / 2}\right) \\
\varepsilon_{s . y}\left(t_{i+1 / 2}\right)=\varepsilon_{c f}\left(t_{i+1 / 2}\right)+\left[\varepsilon_{e l . y}\left(t_{i+1 / 2}\right)-v \cdot \varepsilon_{e l . x}\left(t_{i+1 / 2}\right)\right]+\varepsilon_{p l . y}\left(t_{i+1 / 2}, t_{0}\right)+\varepsilon_{c u m . y}\left(t_{(i-1)+1 / 2}\right)
\end{array}\right.
$$

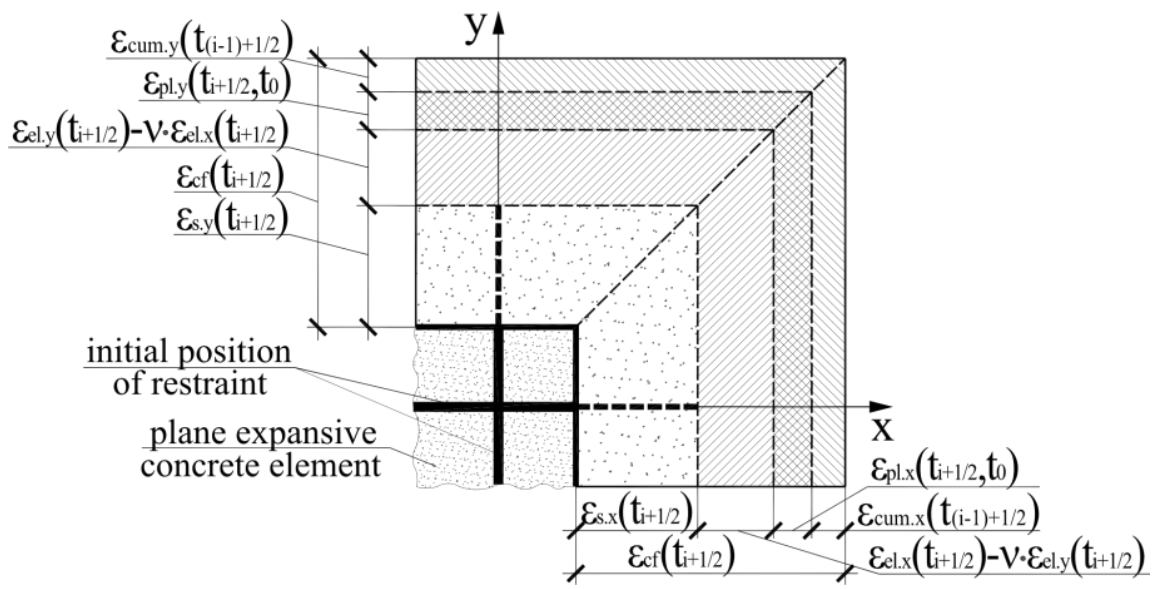

Fig. 1. Development of strains in the plane expansive concrete element.

3) the equilibrium condition between resultant forces in restrained reinforcement and expansive concrete section takes place in directions $X$ and $Y$ at any $i$-th time interval.

The increment of restrained expansion strains in direction $X$ and direction $Y$ is calculated as follows:

$$
\left\{\begin{array}{r}
\left(\Delta \varepsilon_{s . x}\right)_{i}=\left(\Delta \varepsilon_{c f}\right)_{i}-\left[\left(\Delta \sigma_{c . x}\right)_{i}-v \cdot\left(\Delta \sigma_{c . y}\right)_{i}\right] \cdot J\left(t_{i+1 / 2}, t_{i}\right)- \\
-\sum_{j=1}^{i-1}\left[\left(\Delta \sigma_{c . x}\right)_{j} \cdot \frac{\Delta \varphi\left(t_{i}, t_{j}\right)}{E_{c .28}}\right]-\frac{\sum_{j=1}^{i-1}\left(\Delta \sigma_{c . x}\right)_{j}}{E_{c}\left(t_{(i-1)+1 / 2}\right)} \\
\left(\Delta \varepsilon_{s . y}\right)_{i}=\left(\Delta \varepsilon_{c f}\right)_{i}-\left[\left(\Delta \sigma_{c . y}\right)_{i}-v \cdot\left(\Delta \sigma_{c . x}\right)_{i}\right] \cdot J\left(t_{i+1 / 2}, t_{i}\right)- \\
-\sum_{j=1}^{i-1}\left[\left(\Delta \sigma_{c . y}\right)_{j} \cdot \frac{\Delta \varphi\left(t_{i}, t_{j}\right)}{E_{c .28}}\right]-\frac{\sum_{j=1}^{i-1}\left(\Delta \sigma_{c . y}\right)_{j}}{E_{c}\left(t_{(i-1)+1 / 2}\right)}
\end{array}\right.
$$

where $\left(\Delta \sigma_{c . x}\right)_{i}$ and $\left(\Delta \sigma_{c . y}\right)_{i}-$ increment of self-stress at the $i$-th time interval in direction $X$ and direction $Y$ accordingly;

$\left(\Delta \sigma_{c . x}\right)_{j}$ and $\left(\Delta \sigma_{c . y}\right)_{j}-$ increment of self-stress at the $j$-th time interval in direction $X$ and direction $Y$ accordingly;

$\left(\Delta \varepsilon_{c f}\right)_{i}$-increment of free strain of expansive concrete at the $i$-th time interval; 
$E_{c .28}$ - Young's modulus of expansive concrete at 28 days in temperature adjusted concrete age;

$E_{c}\left(t_{(i-1)+1 / 2}\right)$ - Young's modulus of expansive concrete at $\left(t_{(i-1)+1 / 2}\right)$ days in temperature adjusted concrete age;

$J\left(t_{i+1 / 2}, t_{i}\right)$ - creep compliance function;

$\Delta \varphi\left(t_{i}, t_{j}\right)$ - increment of creep coefficient of expansive concrete at the $i$-th time interval under constant self-stress applied at the $j$-th time interval.

According to [8], creep compliance function $J\left(t_{i+1 / 2}, t_{i}\right)$ should be determined by the formula:

$$
J\left(t_{i+1 / 2}, t_{j}\right)=\frac{1}{E_{c}\left(t_{j}\right)}+\frac{\varphi\left(t_{i+1 / 2}, t_{j}\right)}{E_{c .28}}
$$

where $E_{c}\left(t_{j}\right)$ - Young's modulus of expansive concrete in temperature adjusted concrete age of $t_{j}$ days;

$\varphi\left(t_{i+1 / 2}, t_{j}\right)$ - creep coefficient of expansive concrete at the age of $t_{i+1 / 2}$ days due to the self-stress applied at the age of $t_{j}$ days.

Creep coefficient $\varphi\left(t, t_{0}\right)$ of expansive concrete at early age depends on the notional creep coefficient $\varphi_{0}$ and coefficient $\beta_{c}\left(t, t_{0}\right)$ and calculated by the formulas in [8]:

$$
\begin{gathered}
\varphi\left(t, t_{0}\right)=\varphi_{0} \cdot \beta_{c}\left(t, t_{0}\right) \\
\varphi_{0}=5.31 \cdot\left(E_{c}\left(t_{0}\right) / E_{c .28}-1\right)^{2}+1.11 \\
\beta_{c}\left(t, t_{0}\right)=\left[\frac{t-t_{0}}{\beta_{H}+\left(t-t_{0}\right)}\right]^{0.3}
\end{gathered}
$$

In formulas $(6,7)$ the next parameters are adopted:

$E_{c}\left(t_{0}\right) / E_{c .28}$ - relative Young's modulus;

$\beta_{c}\left(t, t_{0}\right)$ - coefficient that describes the creep at temperature adjusted concrete age $t$ after temperature adjusted concrete age of loading $t_{0}$;

$\beta_{u}-$ coefficient that depicts the effect of loading age on the creep development and is calculated according to the formulas in [8]:

$$
\left\{\begin{array}{l}
\beta_{u}=0.000001, \text { if } 0 \leq E_{c}(t) / E_{c .28}<0.346 \\
\beta_{u}=40.5 \cdot\left(\frac{E_{c}(t)}{E_{c .28}}-0.346\right)+0.485, \text { if } 0.346 \leq E_{c}(t) / E_{c .28}<1.0
\end{array}\right.
$$

Taking into account formulas (5-7), the increment of creep coefficient can be calculated by:

$$
\Delta \varphi\left(t_{i}, t_{j}\right)=\varphi\left(t_{i+1 / 2}, t_{j}\right)-\varphi\left(t_{(i-1)+1 / 2}, t_{j}\right)
$$


In general case Young's modulus of expansive concrete at early age is defined in accordance with the expression in [8]:

$$
E_{c}(t)=E_{c .28} \cdot \exp \left(s\left(1-\left(\frac{t_{e .28}-a}{t-a}\right)^{0.5}\right)\right)
$$

where $s, a$-empirical coefficients;

$t$ - temperature adjusted concrete age:

$$
t=\sum_{i=1}^{n} \Delta t_{i} \cdot \exp \left[13,65-\frac{4000}{273+T\left(\Delta t_{i}\right) / T_{0}}\right]
$$

where $\Delta t_{i}$ - number of days where a temperature $T\left({ }^{\circ} \mathrm{C}\right)$ prevails; $T\left(\Delta t_{i}\right)$ - temperature in $\left[{ }^{\circ} \mathrm{C}\right]$ during the time period $\Delta t_{i} ; T_{0}=1{ }^{\circ} \mathrm{C}$.

It should be pointed out that expansive concrete and reinforcement deform compatibly because of the bond conditions, so the increments of self-stresses at the $i$-th time interval in directions $X$ and $Y$ are calculated by:

$$
\left\{\begin{array}{l}
\left(\Delta \sigma_{c . x}\right)_{i}=\left(\Delta \varepsilon_{s . x}\right)_{i} \cdot E_{s . x} \cdot \rho_{s . x} \\
\left(\Delta \sigma_{c . y}\right)_{i}=\left(\Delta \varepsilon_{s . y}\right)_{i} \cdot E_{s . y} \cdot \rho_{s . y}
\end{array}\right.
$$

where $E_{s . x}$ and $E_{s . y}$ - Young's modulus of reinforcement in direction $X$ and direction $Y$ accordingly;

$\rho_{s . x}$ and $\rho_{s . y}$ - reinforcement ratio in direction $X$ and direction $Y$ accordingly.

The total values of the restrained expansion strains and self-stresses in direction $X$ and direction $Y$ at given time interval are obtained as follows:

$$
\left\{\begin{array}{l}
\left(\varepsilon_{s . x}\right)_{i}=\left(\varepsilon_{s . x}\right)_{i-1}+\left(\Delta \varepsilon_{s . x}\right)_{i} \\
\left(\varepsilon_{s . y}\right)_{i}=\left(\varepsilon_{s . y}\right)_{i-1}+\left(\Delta \varepsilon_{s . y}\right)_{i}
\end{array} ;\left\{\begin{array}{l}
\left(\sigma_{c . x}\right)_{i}=\left(\sigma_{c . x}\right)_{i-1}+\left(\Delta \sigma_{c . x}\right)_{i} \\
\left(\sigma_{c . y}\right)_{i}=\left(\sigma_{c . y}\right)_{i-1}+\left(\Delta \sigma_{c . y}\right)_{i}
\end{array}\right.\right.
$$

Duration of iterative procedures depends on the free expansion strains development law.

\section{Verification of the design model 2D MSDM}

For the verification of proposed design model the experimental investigations of the plane expansive concrete element during the hardening period were conducted. The experimental results of two-way restrained expansive concrete elements obtained by other authors and presented in papers $[5,14]$ were also analyzed.

Characteristics of materials and geometry of samples, used in test of authors and described in papers $[5,14]$, are presented in the Table 1.

Table 1. Parameters of test specimens 


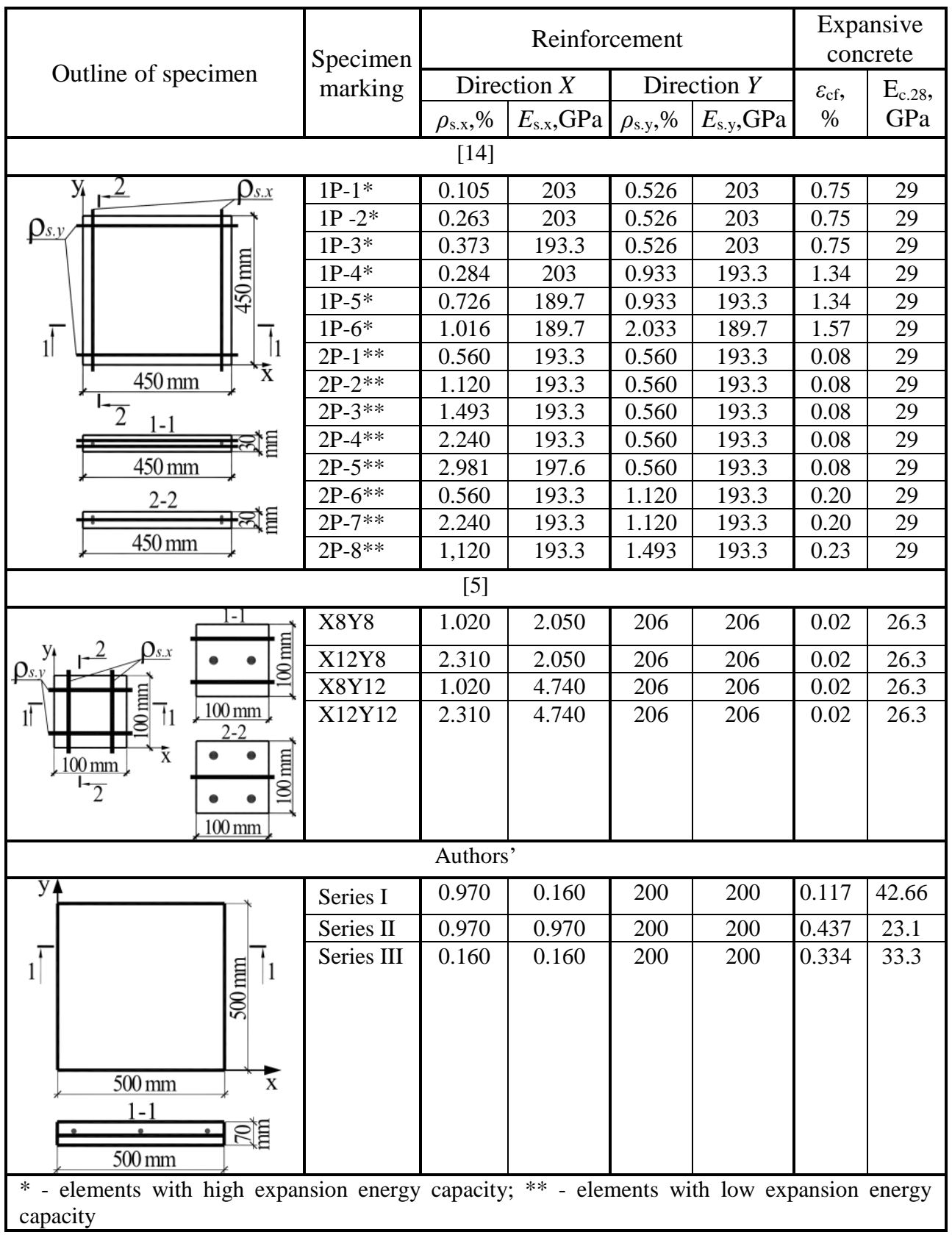

In the Table 1 the following parameters are shown: $\rho_{\text {s.x }}, \rho_{\text {s.y }}-$ reinforcement ratio in direction $X$ and $Y$ accordingly; $E_{\mathrm{s} . \mathrm{x}}, E_{\mathrm{s} . \mathrm{y}}$ - Young's modulus of reinforcement in direction $X$ and $Y$ accordingly; $\varepsilon_{\mathrm{cf}}$ - free expansion strain at the end of expansive concrete stabilization period; $E_{\text {c. } 28}$ - Young's modulus of expansive concrete at 28 age that was defined in unrestraint conditions.

Composition of concrete mix in researches under consideration is presented in the Table 2.

Table 2. Composition of concrete mix of selected test specimens (per $1 \mathrm{~m}^{3}$ ) 


\begin{tabular}{|c|c|c|c|c|c|c|}
\hline Source & \multicolumn{2}{|c|}{ Expansive binder, $\mathrm{kg} / \mathrm{m}^{3}$} & $\begin{array}{c}\text { Fine } \\
\text { aggregate, } \\
\mathrm{kg}\end{array}$ & \begin{tabular}{|c|} 
Coarse \\
aggregate, \\
$\mathrm{kg}$
\end{tabular} & $\begin{array}{c}\text { Water, } \\
\mathrm{kg}\end{array}$ & $\mathrm{W} / \mathrm{C}$ \\
\hline \multirow{3}{*}{ [14] } & Cement CEM I 42,5R - 79\% & \multirow{3}{*}{1120} & \multirow{3}{*}{1120} & \multirow{3}{*}{ - } & \multirow{3}{*}{360} & \multirow{3}{*}{0.32} \\
\hline & High-alumina cement $-12 \%$ & & & & & \\
\hline & Gypsum - 9\% & & & & & \\
\hline \multirow{2}{*}{ [5] } & Cement & 298 & \multirow{2}{*}{830} & \multirow{2}{*}{951} & \multirow{2}{*}{175} & \multirow{2}{*}{0.55} \\
\hline & Expansive additive & 20 & & & & \\
\hline \multirow{3}{*}{ Authors' } & Cement CEM I 42,5R - 74\% & \multirow{3}{*}{500} & \multirow{3}{*}{750} & \multirow{3}{*}{1150} & \multirow{3}{*}{215} & \multirow{3}{*}{0.43} \\
\hline & High-alumina cement $-14 \%$ & & & & & \\
\hline & Gypsum $-12 \%$ & & & & & \\
\hline
\end{tabular}

According to the proposed design model 2D MSDM for all samples, described in the table 1, the restrained expansion strains and corresponding self-stresses from one day to the expansive concrete stabilization were calculated and then compared with experimental results. In the present researches the calculations according to the model [8] were also carried out to demonstrate the necessity of taking into account the additional cumulative force induced by the restraint. It's noticeable that the more level of restraint and energy capacity of expansive concrete are used the more disagreement between experimental and calculated in accordance with the model [8] values of the restrained expansion strains and self-stresses appears.

At the same time, a good agreement has been observed concerning the experimental and theoretical values of the restrained expansion strains and self-stresses calculated according to the model 2D MSDM. For example, in the authors' researches for the series II $\left(\rho_{\mathrm{s} . \mathrm{x}}=0,97 \%, \rho_{\mathrm{s} . \mathrm{y}}=0,97 \%, \varepsilon_{\mathrm{cf}}=0,437 \%\right)$ the maximum difference between experimental and calculated according to the model 2D MSDM values of the restrained expansion strains in direction $\mathrm{X}$ and direction $\mathrm{Y}$ are $7,8 \%$ and $6,7 \%$ correspondingly. When performing the design model [8], the maximum difference between the same parameters are $107,9 \%$ and $105,7 \%$ correspondingly. With reference to the low level of restraint and low energy capacity of expansive concrete, as in case of series I in direction $\mathrm{Y}\left(\rho_{\mathrm{s} . \mathrm{y}}=0,16 \%\right.$, $\varepsilon_{\mathrm{cf}}=0,117 \%$ ) the maximum difference between experimental and calculated according to the model 2D MSDM and model [8] values of the restrained expansion strains are 4,74\% and $16,8 \%$ correspondingly.

Figures 2-4 shows the development in time of the experimental and theoretical values of the restrained expansion strains for some test specimens with high and low levels of restraint calculated under the proposed model and model [8].

The uncertainty of the proposed design model assesses according to the requirements in codes [16]. Figure 5 presents the comparison of the experimental and theoretical values of the restrained expansion strains by the end of the stabilization period for all test samples from table 1 calculated according to the model 2D MSDM. Figure 5 shows also the values of the restrained expansion strains calculated under the model [8]. 


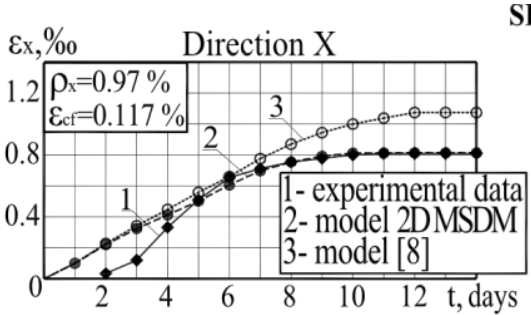

SERIES I
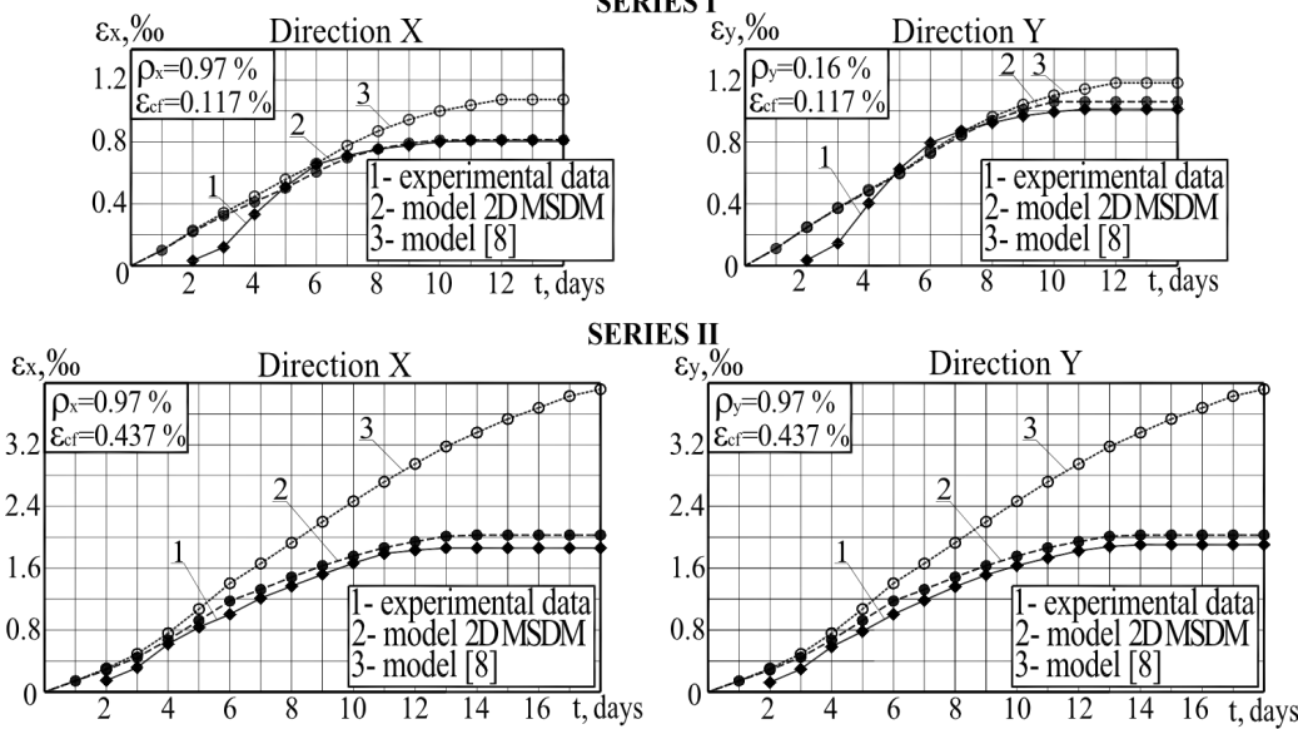

Fig. 2. Development in time of the restrained expansion strains for the series I and series II in the authors' researches.
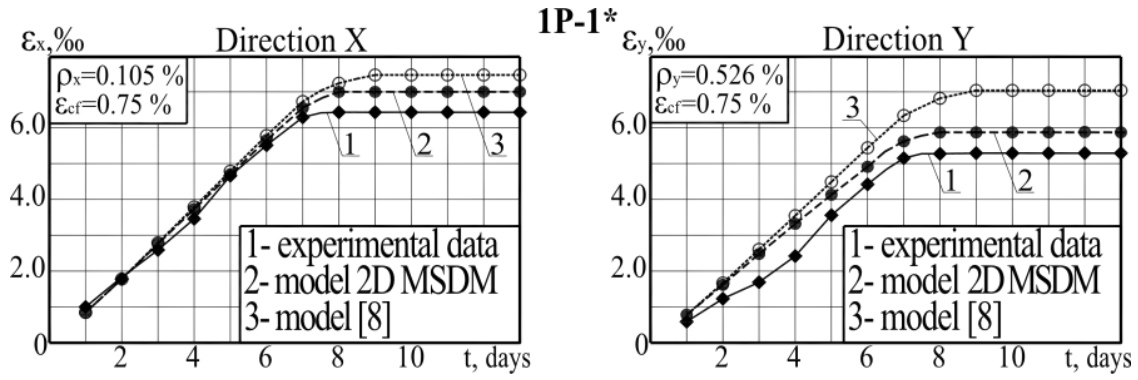

Fig. 3. Development in time of the restrained expansion strains for sample $1 \mathrm{P}-1^{*}$.
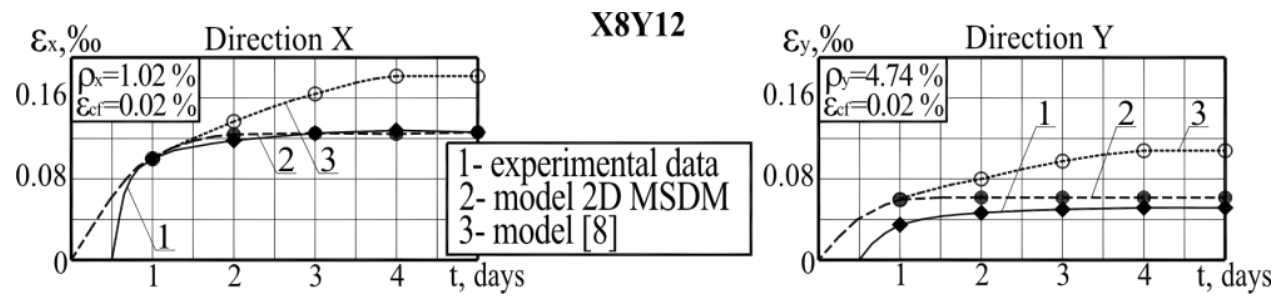

Fig. 4. Development in time of the restrained expansion strains for sample X8Y12.

According to [15], with respect to the proposed model 2D MSDM the coefficient of variation of the error term equals $V_{\delta}=14,7 \%$. In respect of the model [8], that doesn't take into account the additional cumulative force, the coefficient of variation of the error term equals $V_{\delta}=24 \%$. 


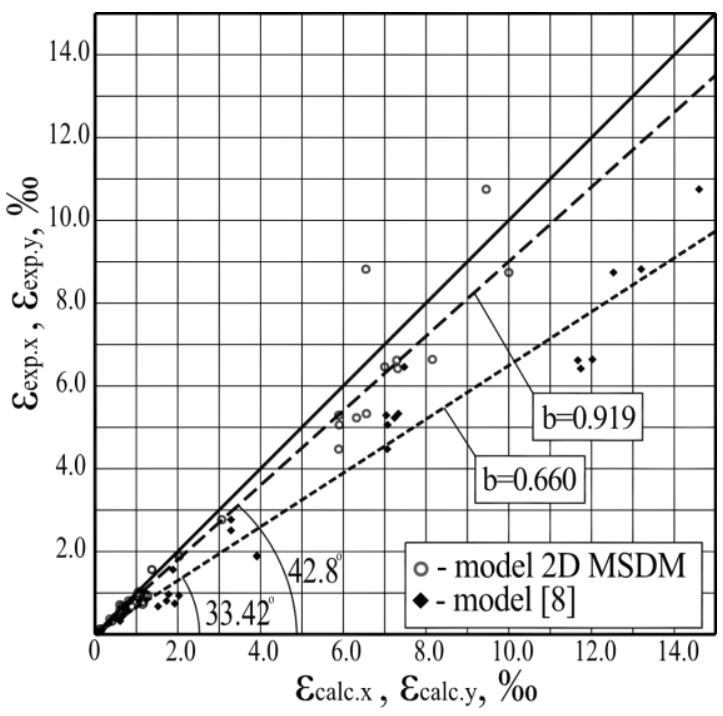

Fig. 5. Comparison of the experimental and calculated values of the restrained expansion strains by the end of stabilization period in direction $\mathrm{X}$ and direction $\mathrm{Y}$.

\section{Conclusions}

1. A design model for assessment the restrained expansion strains and self-stresses in case of two-way restraint conditions (2D MSDM) has been developed. The model 2D MSDM allows determining the restrained expansion strains and corresponding self-stresses from the one day to the expansive concrete stabilization with taking into account the elasticplastic behavior of expansive concrete.

2. The consistency of 2D MSDM was confirmed by the results of experimental investigations of two-way restrained expansive concrete elements carried out by authors and other researchers: the coefficient of variation of the error term equals $V_{\delta}=14,7 \%$.

\section{References}

1. V. Sannikava, V. Tur, J. Sustain. Archit. Civ. Eng., 20, 11 (2017), doi: http://dx.doi.org/10.5755/j01.sace.20.3.19082

2. V. V. Tur, V. H. Sannikava, Bud. Archit., 19, 7 (2020), Doi:10.35784/bud-arch.2131

3. V. Mikhailov, S. Litver, Expansive and Self-stressing Cements and Self-stressed Reinforced Structures (Moscow: Stroyizdat, 1974)

4. TCP 45-5.03-158-2009 Concrete and reinforced concrete structures from self-stressing concrete (Minsk, 2010)

5. Y. Ishikava, K. Shibata, T. Tanabe, Creep, Shrinkage and Durability Mechanics of Concrete and Concrete Structures, 6 (London, 2009)

6. T. Man, T, B. Wang, H. Jin, X. Zhang, Constr. Build. Mater., 128, 8 (2016)

7. K. Okada, M. Ohta, T. Nagafuchi, A. Yata, S. Tamai, J. Soc. Mater. Sci., 32, 5 (Japan, 1983)

8. H. Ito, I. Maruyama, M. Tanimura, R. Sato, J. Adv. Concr. Technol., 2, 19 (2004) 
9. V. Semianiuk, V. Tur, M. F. Herrador, G. M. Paredes, Constr. Build. Mater., 131, 10 (2017)

10. K. Z. Truman, D. J. Petrushka, C. D. Norman, J. Eng. Mech., 117, 14 (June 1991)

11. R. P. Carmichael, Project Final Report ENGR 082 (Swarthmore College, department of engineering, 2009)

12. G. De Schutter, L. Taerwe, Mater. Struct., 29, 9 (July 1996)

13. J. Byfors, Plane concrete at early ages (Stockholm, 1980)

14. V. Marchuk, Strains and stresses of plane self-stressing concrete elements under nonsymmetrical biaxial restraint at the expansion stage: PhD thesis (Brest, 2002)

15. TCP EN 1990-2011 (02250) Eurocode. Basis of structural design (Minsk, 2012) 